\title{
Ethnic Identity and Career Aspiration of the Taiwanese Indigenous Students in the Era of Globalization
}

\author{
Shan-Hua Chen ${ }^{1}$, Cheng-Cheng Yang ${ }^{1}$, Hsuan-Fu Ho ${ }^{1}$ \& Li-Ping Wang ${ }^{1}$ \\ ${ }^{1}$ National Chia-Yi University, Taiwan \\ Correspondence: Cheng-Cheng Yang, National Chia-Yi University, Taiwan. E-mail: yccjason@gmail.com
}

Received: March 30, 2012

Accepted: May 3, $2012 \quad$ Published: August 1, 2012

doi:10.5539/ass.v8n10p23

URL: http://dx.doi.org/10.5539/ass.v8n10p23

\begin{abstract}
This study is endeavored to explore the ethnic identity perceived by elite indigenous students studying at senior high schools, to examine their career aspiration, and to investigate their involvement in traditional cultural activities. The connotations of ethnic identity, four identity statuses theory, model of ethnic identity development and ethnic minority identity were reviewed. The results provided data for analyzing how certain activities may affect the ethnic identification process. Future research might replicate the methodology of this study with a specific focus on different types of high school.
\end{abstract}

Keywords: ethnic identity, ethnic identification, indigenous high school, globalization, Taiwan

\section{Introduction}

Due to the impact of cultural globalization, many unique forms of folk culture and society are facing danger of disappearing. For example, American natives would face a sense of emotional dislocation when they left their homeland. This kind of feeling would hinder their success when they pursue their academic or career goals (Griffin-Pierce, 1997). Benjamin, Chambers, and Reiterman (1993) also noted the difficulty of American natives to persist their college education. Taiwan is no exception with this global trend. Although most indigenous people are still living tribally in remote mountainous areas, their traditional culture and indigenous identities are quickly fading away, and their living style has moved toward a so called international style.

The indigenous population living in the tribes in Taiwan has increased dramatically recently. This increase can be attributed to the newly enforced governmental policy of protection of ethnic minorities. Those who failed to register as citizens when they were born have recently completed the birth registration process to enjoy the benefits of the new policy. The globalized labor market also contributed greatly to the population increase. The indigenous people who used to work as lower-paying labors in the city lost their job to even-lower-cost foreign labors, forcing them to migrate back to their tribes.

The Taiwan government has introduced many policies to protect the human rights and culture of the indigenous groups with a specific focus on education: offering vocational training and employment advice to indigenous people; encouraging careers related to traditional arts and crafts production; re-building traditional rituals, festivals and celebrations; and educating indigenous students to succeed in the forthcoming globalization competitions, and so forth.

Despite all the efforts did by the government, the educational achievement and self-confidence of the indigenous students is still much lower than their mainstream counterparts in Taiwan. This phenomenon has to be further revamped if our aim is to promote cultural balance and variety, and to protect the human rights as a whole. This study is thus endeavored to explore the ethnic identity perceived by elite indigenous students studying at senior high schools, to examine their career aspiration, and to investigate their involvement in traditional cultural activities.

\section{Objectives of the Study}

Based on the above introduction, the purposes of this study were as follows: 
First, to explore the elite indigenous high school students' ethnic images, attitudes, and participant in ethnic cultural activities

Second, to examine the ethnic identification differences of the indigenous high school students with different genders

Third, to understand the connections between indigenous students' ethnic identity and their career aspirations

\section{Literature Review}

Literature review of this study firstly reviews the theoretical framework which includes the connotations of ethnic identity, four identity statuses theory, model of ethnic identity development, and the model of ethnic minority identity. The second section is the review of related empirical studies.

\subsection{Theoretical Framework}

\subsubsection{The Connotations of Ethnic Identity}

Ethnic identity is based on the identity of ethnic group and race. Ethnic identity usually combines with varied cultural characteristics in different races (Hsu, 1990). In this research, ethnic identity is defined as the indigenes identify themselves as members of their ethnic origin, and have synesthesia with their ethnic peer group. Moreover, they often take part in the common cultural activities.

\subsubsection{James Marcia and the Four Identity Statuses Theory}

Marcia(1966) suggested that there are four types of identity statuses: (1) Identity diffusion: the adolescents are neither exploring nor making any commitments. (2)Identity foreclosure: the adolescents have made a commitment, but not had any opportunity to experience alternatives, nor be conscious of exploring their own ethnic culture. They are usually influenced by their parents' decision. (3) Identity moratorium: the adolescent have experienced different roles, but still not had any commitment. They are on the verge of identity crisis. (4) Identity achievement: it is the final status where the adolescent have involved in exploring different roles and opportunities. The adolescents have made their decisions for life.

\subsubsection{Jean Phinney and the Model of Ethnic Identity Development}

Phinney(1989) divided ethnic identity development into three stages: (1) Unexamined ethnic identity: the adolescents had not explored their ethnicity. (2) Ethnic identity search/ moratorium: through exploring, individuals have started a search into formation of ethnic identity. (3)Ethnic identity achievement: when young people achieve the phase, they would accept their own ethnicity and achieved mature and steady cultural identification.

\subsubsection{Nimmi Hutnik and the Model of Ethnic Minority Identity}

Hutnik (1991) divided ethnic identity in accordance with one's own minority culture and the dominant ethnic group culture into four types: (1)Acculturative: young people accept both one's own ethnic culture and mainstream culture, and has the ability to integrate the adaptation; (2)Assimilative: young people abandon one's own ethnic culture and whole-heartedly accept the cultural norms of dominant groups; (3)Marginal: young people do not accept the mainstream culture, and also lose the ethnic and cultural heritage; (4)Dissociative: young people exclude and resist to the culture of the majority ethnic group, but have strong solidarity to the traditional ethnic culture.

\subsection{Ethnic Identity and Career Aspiration of Indigenous Students: Perspectives of Empirical Studies}

Ethnic identity, as pointed out by Phinney (1990), is a multidimensional construct which reflects personal identification and sense of attachment with their ethnic group. The development of ethnic identity is highly influenced by the cultural context, such as family and community contexts (Kvernmo and Heyerdahl, 2004). In Kvernmo and Heyerdahl's (2004) study, they surveyed two ethnic groups, indigenous Norwegian Sami and ethno-cultural Kven. Their survey's samples are mostly adolescents. They found that indigenous adolescents have stronger ethnic identity when they are compared with the other adolescents. They also found that the competence in ethnic language has positive relationship with indigenous adolescents' sense of ethnic identity.

Witherspoon, Speight, and Thomas (1997) applied an empirical study approach to find out the relationship between racial identity attitudes, school achievement, and academic self-efficacy. Their targeted sample group is African American high school students. In fact, in other studies, such as Fordham (1988) and Ward (1990), they did not have a consensus on the research question: how will ethnic identity influence indigenous students' academic achievement? In Witherspoon, Speight, and Thomas's study (1997), they found that although black students' ethnic identity has a positive relationship with their academic achievement, there are some other 
findings in their regression models. In their study, only the variable of immersion attitudes is a positive predictor of academic achievement, whereas the variables of pre-encounter attitudes and internationalization attitudes are not significant. This reflects a finding that a variety of racial identity attitudes exists among black adolescents. Thus the authors suggest future studies to apply a qualitative approach to investigate how indigenous students really think and how they response to the value of mainstream society.

Other studies also explored the gaps of college access, school achievement, and aspiration between indigenous students and others (Hossain, Gorman, Williams-Mozely, Garvey, 2008). Cheng and Jacob (2008) compared ethic identity and career aspiration among Taiwanese Aborigines and American Indians, they found in the context of American society which is a relatively higher multi-culturalized society, teachers and peers will have a relatively lower sense of stereotype and racial discrimination on indigenous students. Both the governments in Taiwan and the United States try to implement affirmative action policies. But, it is more favorable by the Taiwanese Aborigines. The reason why the Taiwanese Aborigines would be more likely to accept the affirmative action policies is an interesting topic for qualitative inquiry.

\section{Methodology}

In the process of this study, the authors adopted the participant observation to collect data and held several group interviews with some elite indigenous high school students.

\subsection{Participants}

Most indigenous people's economic condition is not good, thus most indigenous students would choose vocational training during school years. They hope they can enter the job market as soon as possible and improve their original families' economic condition. But, still some indigenous families would help their children attend schools with better quality, though these schools are private and charge higher tuition. For example, some indigenous girls choose "Tanivu girl school" and some indigenous boys choose "Pasuya high school". These two schools are local academic-oriented high schools. This study choose indigenous students enrolled in these two schools as research participants because these students are elites in their tribes and will attend universities in the near future.

Most of the indigenous students of the two schools come from the tribes of Tsou people who lived in Ali-Mountain. The number of subjects of these two schools and the distribution of tribes are as follows:

Table 1. The tribes of the two school students in 2010

\begin{tabular}{ccc}
\hline Schools Tribe & Tanivu Girl school & Pasuya High School \\
\hline Lalauya Tribe & 0 & 3 \\
Tapangu Tribe & 3 & 2 \\
Saviki Tribe & 3 & 1 \\
Niahosa Tribe & 1 & 1 \\
Tfuya Tribe & 3 & 2 \\
Pnguu Tribe & 1 & 0 \\
Dama-luwan Tribe & 0 & 1 \\
Total & 11 & 13 \\
\hline
\end{tabular}

\subsection{Methods}

\subsubsection{Observation}

The observation of this study consisted of two parts: the observation of tribal rituals, and the observation of their participation in the school evening-study programs. The main rituals of Tsou are Homeyaya, Mayasvi, and Fo'na festival. The authors not only took part in Tsou's cultural activities, but also observed the participating indigenous youths, including the elite ones. The researcher would prepare and went to the tribes two days before the cultural activities and ceremonies. The researcher would observe their preparation of food, wine, plates for pray, traditions, and indigenous people's attitudes.

The main observation focuses of the evening studies were the peer interactions among indigenous students, the learning of indigenous languages, the practice of ethnic cultures, and their cultural identity buildings. The school observation period was between September, 2010 and June, 2011. In this period of time, the researcher would go to the schools one day per week, from $6: 30 \mathrm{pm}$ to $8: 30 \mathrm{pm}$. Sometimes, the school would arrange study time, 
sometimes the students would learn their native language, or dancing and singing activities. These school activities are the focus of this study.

By the observation results, the authors designed the semi-structured questions for group interviews.

\subsubsection{Group Interviews}

This study conducted twelve times of group interview which include six times group interviews for boy students and six times for girl students. The researchers firstly developed some descriptive questions to ask the students, such as indigenous students' daily activities and using of native language, we also interested in their adjustment and well-being in the schools. The first six group interviews were conducted in September, 2010. The last six group interviews were conducted in March, 2011. In the last group interviews, we focus on the indigenous students who were relatively more involving in tribal activities. In this study, we tried to understand indigenous students' formation of ethnic identity and career aspiration.

Spradely's method of data analyses was adopted as the main tool for this research. The data collected was then processed for a domain analysis, a taxonomic analysis, a componential analysis, and cultural themes analysis (Spradely, 1979; 1980). Self-reflections were used to assure the research validation.

\section{Finding and Discussion}

In the study, most of the two schools' elite indigenous students' parents are civil servants or employers (officials) in the tribes, and one-third of the parents have earned a college degree. The key findings of this study were as follows.

\subsection{Hunting Activities as an Important Part of Ethnic Culture}

Though hunting is not the modern lifestyle for the indigenous people to cover their living expenses, it is an important traditional cultural heritage. Through the hunting process, the indigenous people inherit the wisdom of their ancestors. Elders taught their young orally about taboos and legends within the hunting context. More boys than girls have the experience of hunting with their father. Several boys said that they went hunting very often (about twenty times). Elders not only introduced some animals, folk medicinal or poisonous plants, but also taught them tribal language.

Jack: We were hunting..... my uncle and father told me something. I did not know how to describe them in common language. Then, he would point out what they are.....

Q: Can you talk more about how your father would use tribal language with you when hunting?

Jack: That is, when I was hurt...bleeding, my father would tell me to find a plant. ...to bite it and apply the juice to the wound

Jack: When Dad saw animals, he would speak tribal language... my dad always taught me to look, then he pointed out to me, and take the shotgun to show me how to do that.... (20100930)

Some families' hunting grounds are very far away. It took them two to three days of arduous travelling to reach their destination. Through the trudge and hunting, they were able to enrich their knowledge about wild animals, folk plants, surroundings, and topography in their hunting fields. Most important of all is to cultivate the young spirit of their ethnicity through the whole hunting process.

There is a clear gender division of laboring, and hunting particularly is the masculine work. However, some girls said that they have a desire to go hunting with their father, but they were often rejected. Only a few girls had rare hunting experience in their childhood. Nevertheless, a huntress recently hunted a wild board by herself, and it is just as difficult even for a man to do that. The huntress has been recognized by the tribe, and this has issue further inspired the indigenous girl students' willingness for participating in the hunting activities.

\subsection{The Ethnic Identity of Indigenous High School Students}

Almost all indigenous young students spent their childhood in the tribe around the Ali-mountains. They went to elementary school in the tribes, and seldom left the mountain until 12 years old when they were forced to enroll in the junior high schools located in the city far away from home.

As a result, it often took them a long time to get used to interact with the non-indigenous students. After a long period of adaption, they gradually noticed the non-indigenous values and develop a bicultural identity through the process of acculturating to the modern culture. Some girl students were high achievements and proud of their ethnic identity. They regarded themselves as those with unique given advantages, such as clear contour, good-looking, multi-tongue and distinguished singing ability. However, they were offended by some negative stereotypes related to the indigenous people perceived by non-indigenous students. 
Wendy: But I do not like to hear that indigenous people are only good at singing and dancing. It sounds like that I am not good at other things.

I: Will the identity of indigenous people make you annoyed?

Tiffany: Some students said that we get good grades and attend good school are because of the preferential policy...I don't like it.

I: Then what do you feel the preferential policy?

Wendy: I think we can make effort by ourselves to enter university. (20110105)

The indigenous boy students also had to stay in the tribes until he had to go to the Pasuya high school located in the city. They were assigned to different classes and they were mixed with other non-indigenous students during the class time. After school, these indigenous boy students were accommodated to live together in the dormitory. The student affairs office readjusted the dormitory policy in 2010, and different ethnic group students were mixed in the same room. Indigenous students protested against this policy, for they hoped to practice tribal language and kept tight relationship with their indigenous peers. They also worried that it might be difficult for them to get alone with the non-indigenous students, and they were especially concerned about their peers could be assimilated by other cultures. It is obvious that students' ethnic consciousness and identify has been significantly aroused.

\subsection{Career Aspirations and Ethnic Identity of Indigenous High School Students}

Academic tracking was enforced when the students starting grade ten in high schools. The participating indigenous students were divided into two tracks: natural science track, humanities and social track. Among them, the boy indigenous students in Pasuya high school all select the social track, which indicated that these boy students' would become police officers, counselors, clergies, or teachers when graduated. They all looked forward to make some contributions to their tribes after their graduation.

Mark: If I pass the teacher examination, I will return to the mountains to teach....

I: Do you want to return to your tribe as a teacher?

Mark: Yes. (20101208)

Among the eleven students in Tanivu girls' school, five girls selected science track, which is different from what was expected because girls in general tend to select social track in Taiwan. This indicated that in addition to be a public servant, some students also want to be the medical personnel, hoping to improve the health of the tribe.

One student wanted to engage in civil engineering because she had witnessed many natural catastrophes that badly damaged her village.

Hebe: ...environmental engineering...because of the disaster caused by strong winds, I want to study civil engineering ... because I live in tribes, and the mayor told me that civil engineering would help the tribe. I can work in the mountains ... my parents also support this idea (20101229).

Most of the students in these two schools committed that they would return to their villages after the completion of their studies. Although some students mentioned that their parents encouraged them to go outside of the village and gained a different life experience, or "to earn more money", they still wanted to return to their tribes to make some contributions.

\section{Conclusion}

In the study, the elite indigenous students studying at reputed private high schools experienced a process of cultural identification. They had positive attitudes and images toward ethnicity. Grew up in tribes, they occasionally had the opportunity to follow their elders for hunting activities, where they learned valuable traditional ethnic cultures. Through the process of traditional activities, the indigenous students learned the conventional wisdom, and increased their self-confidence. They much appreciate their own distinguishing biological features and cultural techniques. Some girl students wanted to participate in traditional tribal activities which are generally exclude women from participation. The indigenous students with bicultural identity were high academic achievements. Most of them were enthusiastic in devoting themselves to their ethnic tribes.

Young indigenous people need to learn their traditional knowledge and cultures in seeking the development of culture inherit in the global era. In this study, those who grew up in tribes occasionally had the opportunity to follow their elder to learn their traditional ethnic cultures. Through the process of cultural learning, the indigenous students inherit the conventional wisdom, and increase their self-confidence. The elite indigenous 
students were enthusiastic in returning to their tribes and contributing themselves to promote their distinguishing traditional cultures.

The research results provided valuable data for analyzing how certain activities may affect the ethnic identification process. Future research might replicate the methodology of this study with a specific focus on different types of high school.

\section{Acknowledgements}

The completion and publication of this study will especially thank the funding support from the National Science Council in Taiwan (NSC 99-2410-H-415-003-) and the suggestions from the peer-reviews of Asian Social Science.

\section{References}

Benjamin, D. P., Chambers, S., \& Reiterman, G. (1993). A focus on American Indian college persistence. Journal of American Indian Education, 32(2), 24-40.

Chen, Chih-Lieh. (1997). The indigenous education in Taiwan. Taipei: Shita Publisher.

Cheng, S. Y., \& Jacob, W. J. (2008). American Indian and Taiwan Aboriginal education: Indigenous identity and career aspirations. Asia Pacific Education Review, 9(3), 233-247. http://dx.doi.org/10.1007/BF03026713

Fordham, S. (1988). Racelessness as a factor in black students' success: Pragmatic victory or pyrrhic victor. Harvard Educational Review, 58, 29-84.

Griffin-Pierce, T. (1997). "When I am lonely the mountains call me": The impact o sacred geography on Navajo psychological well being. American Indian and Alaska Native Mental Health Research, 7(3), 1-10. http://dx.doi.org/10.5820/aian.0703.1997.1

Hossain, D., Gorman, D., Williams-Mozely, J., \& Garvey, D. (2008). Bridging the gap: Identifying needs and aspirations of Indigenous students to facilitate their entry to university. The Australian Journal of Indigenous Education, 37, 9-17.

Hsu, Mu-Chu. (1990). The movement of Taiwan indigenous peoples. In Cheng-Kuang Hsu, \& Wen-Li Sung (Eds.), The emerging social movement in Taiwan (pp.127-151). Taipei: ChuLiu Publisher.

Hutnik, N. (1991). Ethnic minority Identity: A sociological perspective. New York: Oxford University.

Kvernmo, S., \& Heyerdahl, S. (2004). Ethnic identity and acculturation attitudes among indigenous Norwegian sami and ethnocultural kven adolescents. Journal of Adolescent Research, 19, 512-532. http://dx.doi.org/10.1177/0743558403259991

Marcia, J. (1966). Development and validation of ego-identity status. Journal of Personality and Social Psychology, 3, 551-558. http://dx.doi.org/10.1037/h0023281

McCarthy, C. (1997). Nonsynchrony and social difference: An alternative to current radical accounts of race and schooling. In Halsey, A. H., Lauder, H., Brown, P., \& Wells, A. S. (Eds.), Education, culture, economy and society. Oxford University Press.

Phinney, J. S. (1989). Stages of ethnic identity development in minority group adolescents. Journal of Early Adolescence, 9, 34-49. http://dx.doi.org/10.1177/0272431689091004

Phinney, J. S. (1990). Ethnic identity in adolescents and adults: A review of research. Psychological Bulletin, 108, 499-514. http://dx.doi.org/10.1037/0033-2909.108.3.499

Spradley, J. P. (1979). The ethnographic interview. New York: Harcourt Brace Jovanoich College Publishers.

Spradley, J. P. (1980). Participant observation. New York: Holt, Rinehart and Winston.

Ward, J. V. (1990). Racial identity formation and transformation. In C. Gilligan, N. D. Lyons, \& T. J. Hanmer (Eds.), Making connections: The relational worlds and adolescent girls at Emma Willard School. Cambridge, MA: Harvard University Press.

Witherspoon, K. M., Speight, S. L., \& Thomas, A. J. (1997). Racial identity attitudes, school achievement, and academic self-efficacy among African American high school students. Journal of Black Psychology, 23, 344-357. http://dx.doi.org/10.1177/00957984970234003 